\title{
Ozone therapy in painful lipodystrophies. A preliminary study
}

\author{
Olga Cardoso, Pierluigi Rossi, Antonio Galoforo, Guido Collodo \\ Pio Albergo Trivulzio, Milan; Scientific Society of Oxygen-Ozone Therapy (SIOOT), Gorle (BG), Italy
}

\begin{abstract}
The study focuses on lipomas, which are quite common, occur in one person out of every thousand and generally arise individually, although about $20 \%$ of those who suffer from them may have multiple cases. Ozone oxygen therapy has been shown to be effective and free of adverse side effects in all treated patients, and there are no contraindications to the use of the therapy. In most patients, the lipoma shrinks completely. The oxygen-ozone procedure is a scientifically approved and highly effective treatment for lipodystrophy.
\end{abstract}

\section{Introduction}

Lipodystrophies are conditions in which the growth and distribution of adipose tissues are abnormal. Changes in subcutaneous adipose cells may lead to atrophy or bone tissue tumefaction.

There are structures in which there is an increase of the amount of adipose tissue located in one or several parts of the body: i) Painful lipomatosis, or Dercum's disease, which mainly affects women after menopause, and is characterized by the appearance of accumulations of adipose tissue that is painful to touch, especially in abdominal subcutaneous tissue; ii) Steatopygia where excessive accumulation of fat occurs at the gluteal site; iii) Launois-Bensaude multiple nodular lipomatosis is more frequent in male subjects of adult age, and manifests itself

Correspondence: Olga Cardoso, Scientific Society of Oxygen-Ozone Therapy (SIOOT), via Don Luigi Sturzo 2, 24020 Gorle (BG), Italy. Tel:. 035.19910105.

E-mail: info@ossigenoozono.it

Key words: lipodystrophies; ozone therapy.

Contributions: the authors contributed equally.

Conflict of interest: the authors declare no potential conflict of interest.

Received for publication: 20 April 2018.

Accepted for publication: 21 April 2018.

(C) Copyright O. Cardoso et al., 2018

Licensee PAGEPress, Italy

Ozone Therapy 2018; 3:7510

doi:10.4081/ozone.2018.7510

This article is distributed under the terms of the Creative Commons Attribution Noncommercial License (by-nc 4.0) which permits any noncommercial use, distribution, and reproduction in any medium, provided the original author(s) and source are credited. by the appearance of lipomatous nodules at the nape of the neck, chest and abdomen; iv) Lipoma and lipomatosis.

In other cases, however, there is a reduction of adipose tissue in identified areas: ii) In insulin lipodystrophy there are changes like this in the adipose tissue, corresponding to injection sites; ii) Progressive lipodystophy or Barraquer-Simons disease presents as thinness in body regions that are above the pelvis, while the lower part of the body may be normal, or present an increase in subcutaneous fat deposits (riding pants obesity); iii) some subjects who are particularly at risk for subcutaneous infections (diabetics, drug users, immunosuppressed patients) can present with a lipodystrophy profile.

The cause of these diseases is unknown; they are often related to disorders of the peripheral nervous system; sometimes they are associated with malformative anomalies. The symptomatology is largely algid at the sites of fat accumulation and degeneration, especially on evoked stimulus (pressure). Generally, there is no known effective therapy.

Our study focuses on lipomas, which are quite common and occur in one person in every thousand and generally occur individually, although about $20 \%$ of those who present with them may have multiple cases.

Lipomas are by definition lumps of fat that usually grow between the skin and the underlying layer of muscle. They are composed of fat cells that have the same morphology as normal fat cells and are usually detected at middle age.

They are benign subcutaneous tumors that can grow alone, or a number of them can grow. They are easily recognizable because they are rounded or lobulated swellings and can be moved upon applying pressure to the overlying skin. Many lipomas are small, but can expand up to $6 \mathrm{~cm}$, causing pain and functional limitations. They occur particularly on the neck, the torso and on the extremities of the limbs, but they may appear anywhere on the body.

Surgical treatment is often suggested as the only alternative for this disorder if the lipoma tends to create discomfort, is painful or grows excessively.

In our study, we focused our attention on treating lipomas by using the properties of oxygen-ozone therapy, a technique that uses ozone combined with oxygen, to stimulate and increase the protective mechanisms against the production of free radicals and substances that are toxic to cells. ${ }^{1-4}$ It activates circulation in all the tissues, promoting the release of the oxygen to them, thus delivering various effects: analgesic, anti-inflammatory, antiviral, antibacterial, antifungal, hydrophobic, immunomodifying, lipolysis induction, anti-oedema and stimulating the regeneration of the tissues themselves. ${ }^{5}$ A mixture consisting of $99.99997 \%$ oxygen and $0.00003 \%$ ozone, a much more powerful and active gas, is used. ${ }^{5}$

The characteristics that allow the use of oxygen/ozone therapy for this pathology are: i) Ability to split fatty acids into the double carbon bond by reducing the chains and making them hydrophilic; ii) Ability to bind to the membrane of red blood cells making them more elastic; iii) Ability to eliminate edema due to the hydrophobic effect. 
The aim of our work was to show data related to the effectiveness of treatments using local ozone therapy in patients with lipodystrophy problems; adipose accumulation that involved an inflammatory state with consequent joint pain, fibromyalgia, musculoskeletal disorder, postural misalignment and joint restrictions. ${ }^{6}$

Purpose of the study: the main objective is to propose a valid alternative to surgical treatment in patients with painful or excessively growing lipomas. The secondary objectives are to demonstrate the efficacy and absence of adverse side effects in patients treated with oxygen-ozone therapy.

\section{Materials and Methods}

In our study, 20 patients with painful lipomas, aged between 30 and 80 years were evaluated. 16 patients were female and 4 were male (Figure 1).

The therapy was performed by injecting ozone with a syringe into the lipomatous formation.

The injection was performed, after careful disinfection, by inserting very fine sterile single-use needles into the lipomatous area, using special syringes and ensuring adequate asepsis. We applied $10 \mathrm{cc}$ per spot; the needles used were $27 \mathrm{~g}$ and $4 \mathrm{~mm}$; the concentration was $4 \mathrm{ug}$, on an approximately twice-weekly basis, with a total treatment time of 4-5 weeks. At the end of the infiltrations, gentle massage of the area was initiated and the patient was allowed to rest for 10 minutes. Generally, 10 treatment sessions are performed with a generally biweekly frequency.

Among patients with lipodystrophic diseases, patients with lipomas that cause chronic pain and joint limitations with dysfunction were the ones chosen.

\section{Parameters evaluated}

i) VAS scale, designed to enable the patient to identify his/her level of suffering on a color scale that corresponds to an assessment on the numerical scale where 0 represents the absence of pain and 10 the maximum pain imaginable; ii) Regional site measurement with a centimeter scale.

The assessment was made daily with the survey of the VAS scale and the centimeter measurement at the beginning and at the end of the treatment.

An accurate clinical diagnosis of all patients was performed, as well as an instrumental evaluation using ultrasound and/or MRI where indicated.

\section{Treatment protocol}

After signing informed consent, the patients followed the welldefined course of treatment. ${ }^{7}$

On average, 10 oxygen-ozone sessions were provided, with a 03 out of 4 range concentration, around twice a week with a total treatment time of 4-5 weeks.

The patient was positioned to perform the injections, after a thorough site disinfection. Then, the infiltration was carried out by keeping the needle at a 45-degree angle at the location of the lipomatous formation. At the end of the infiltrations, a gentle massage of the area was done and the patient was allowed to rest for $10 \mathrm{~min}$ utes. $60 \mathrm{cc}$ syringes were used with $27 \mathrm{~g} 4 \mathrm{~mm}$-long ultra-fine needles for intra lipomatous injections.

\section{Exclusion criteria}

Taking into account the complexity of our patient, patients with the following were excluded: severe dementia, aphasia, patients receiving NSAIDs, patients using antalgic polypharmacotherapy and pregnant women.

\section{Results and Discussion}

20 patients with lipomas causing pain and functional limitation were recruited, including patients aged between 30 and 80 years. 16 patients were female and 4 were male (Figure 1).

Oxygen-ozone treatments were carried out using regional intra lipomatous injections.

The mean VAS numeric decrease went from 7 to 1 in 10 sessions in all patients treated, with a notable functional improvement (Figure 2). In all patients a reduction of the lipoma of approximately $4 \mathrm{~cm}$ was recorded (Figures 3-9). All of the patients showed an improvement in motor skills. ${ }^{8}$

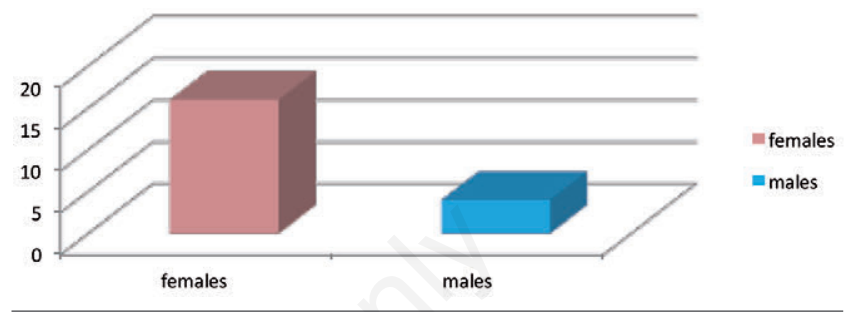

Figure 1. Patients involved in the study: number of females and males.

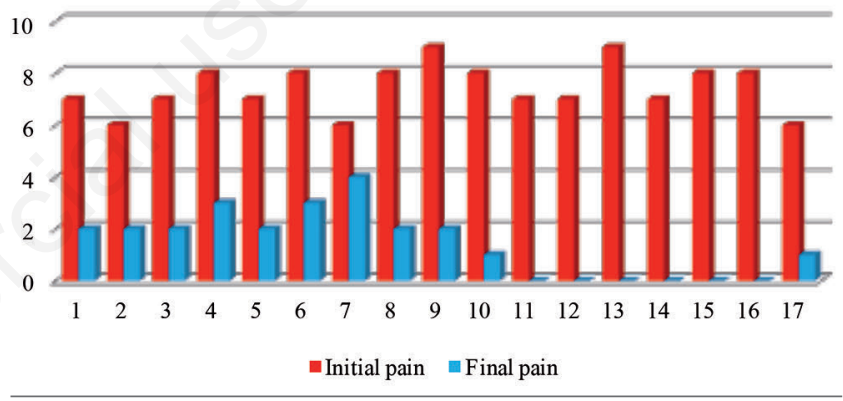

Figure 2. VAS scale numeric decrease.

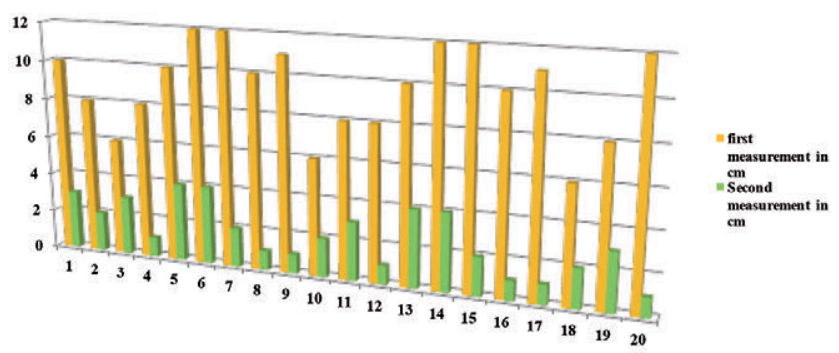

Figure 3. Measuring of lipoma.

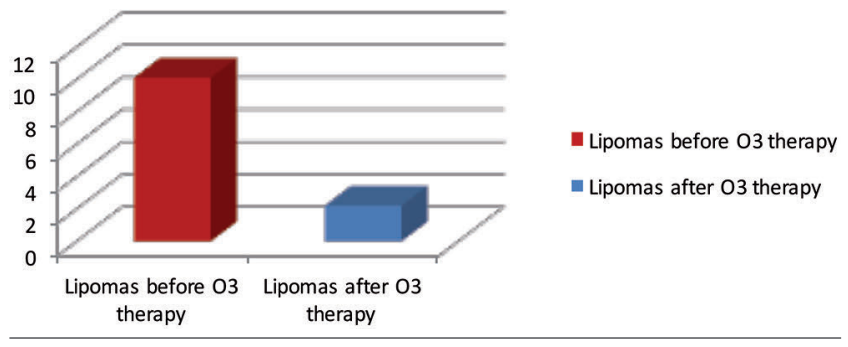

Figure 4. Measurements before and after $\mathrm{O} 3$ therapy in all patients. 


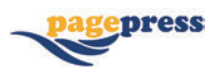

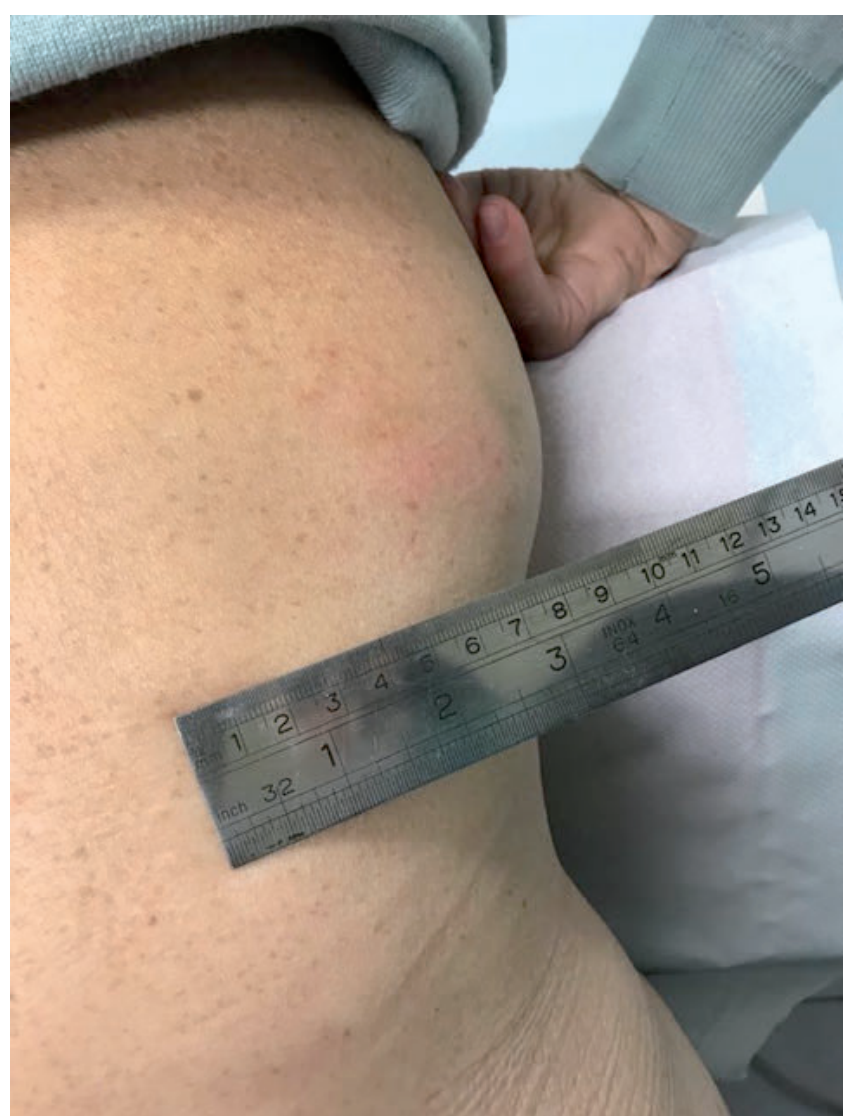

Figure 5. First $\mathrm{cm}$ measurement in one patient.

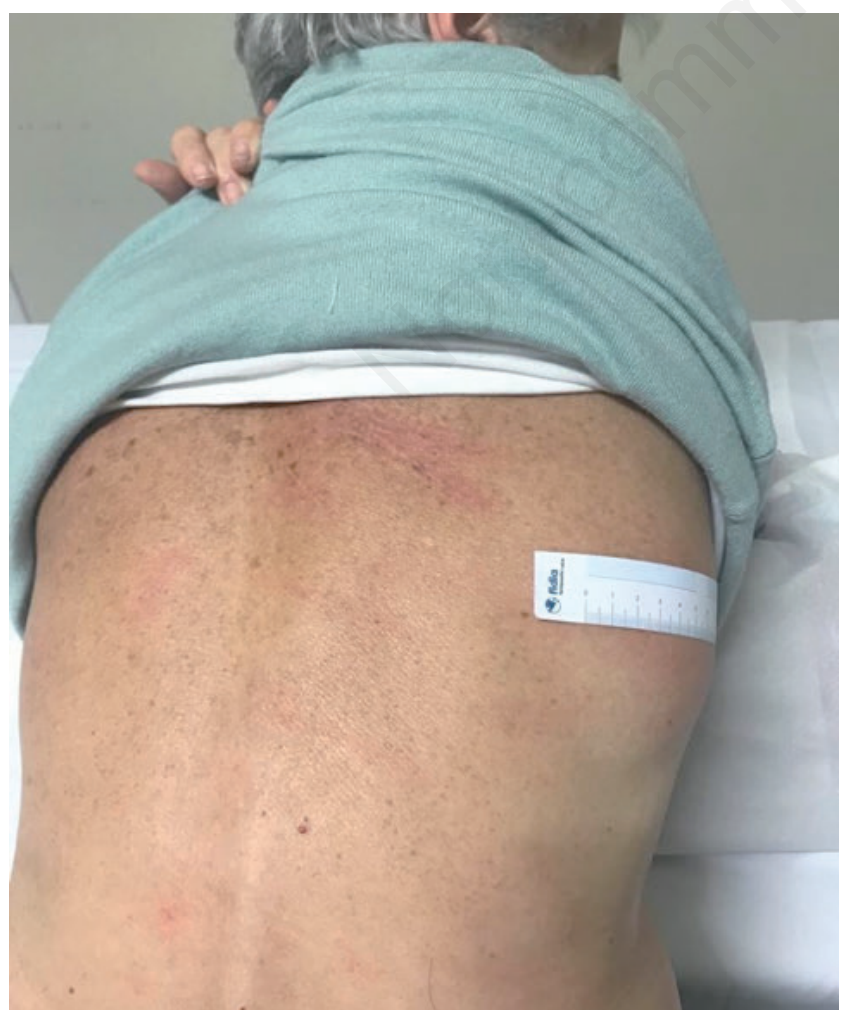

Figure 6. Third $\mathrm{cm}$ measurement in one patient.

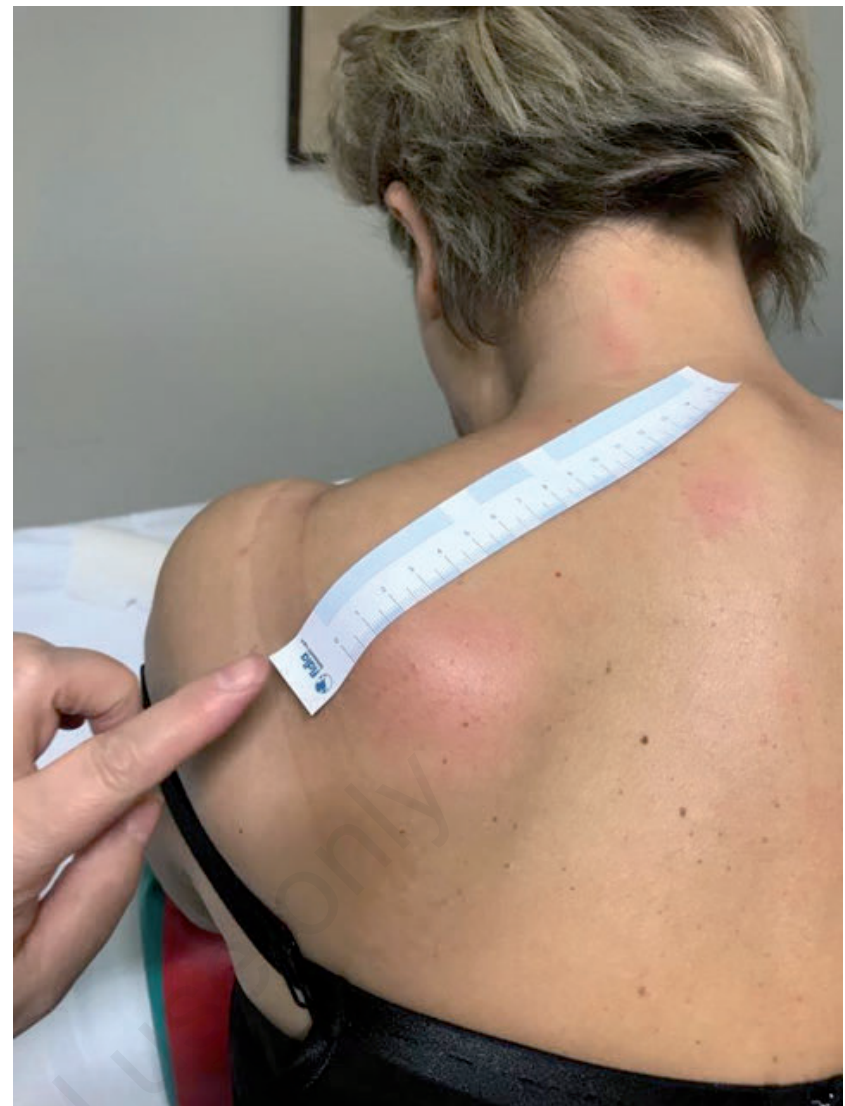

Figure 7. Second $\mathrm{cm}$ measurement in one patient.

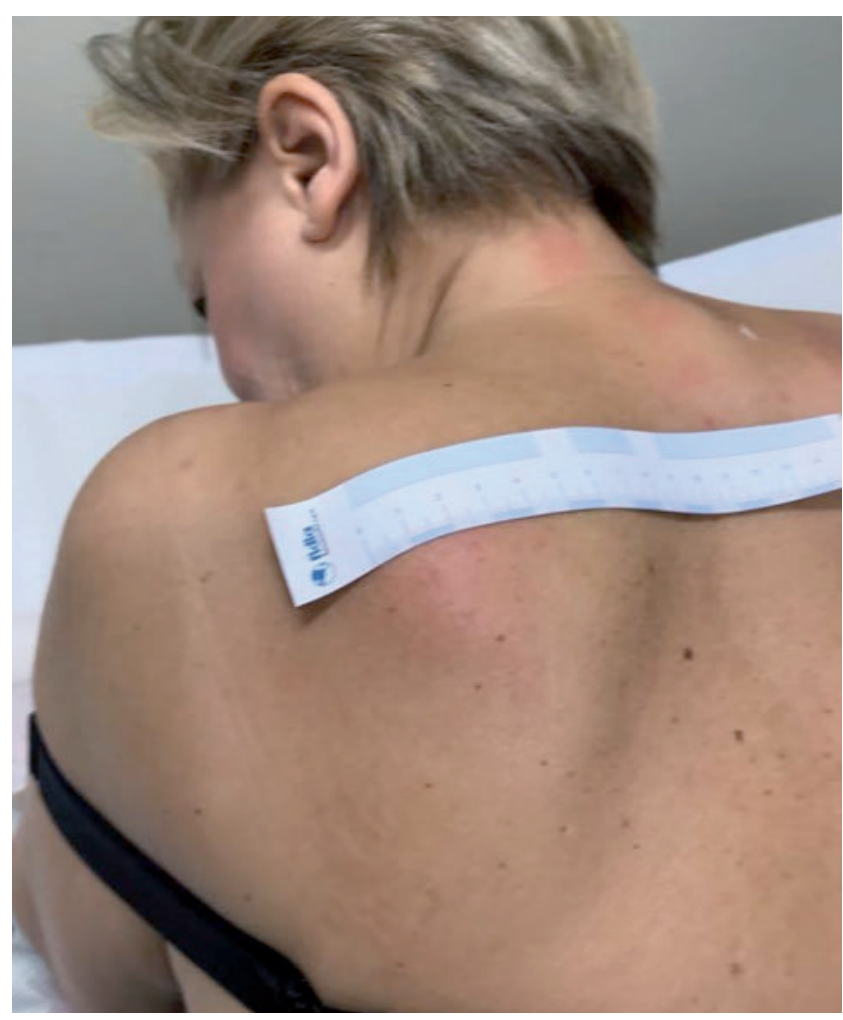

Figure 8. Measurement to finish $\mathrm{O} 3$ treatment. 


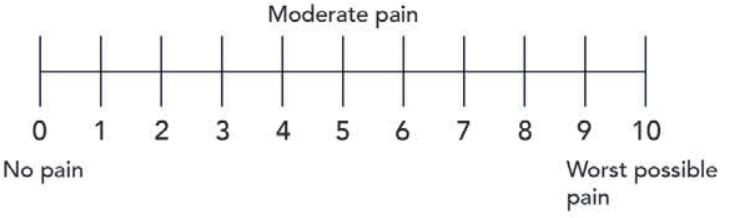

pain

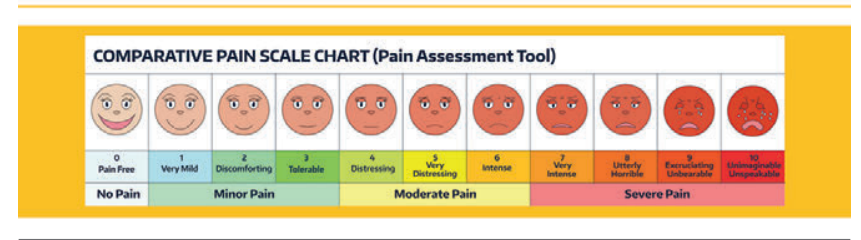

Figure 9. Visual Analogue Scale of pain.

\section{Conclusions}

All patients treated with oxygen-ozone therapy showed motor improvement with greater decrease of pain. Ozone oxygen therapy has been shown to be effective and free of adverse side effects in all treated patients, and there are no contraindications to the use of the therapy. The method is minimally invasive with excellent tolerance and safety even for elderly and even frail patients. In most patients, the lipoma completely shrank.

Oxygen-ozone therapy is a scientifically approved and highly effective treatment for lipodystrophy. This efficacy is achieved as the oxygen-ozone exerts its action through three main mechanisms of action: i) The first mechanism is through ozone itself and carries out the splitting of long fatty acids, making these chains short and therefore hydrophilic; in other words, they easily bind to fluids and therefore are easily expelled through urine; ii) The second mecha- nism of action, also through the oxygen-ozone itself, is carried out in the removal of stagnant interstitial fluids (edema) due either to cellulite or poor circulation; iii) Oxygen-ozone binds to the membrane of red blood cells delivering more oxygen to the various areas and therefore activating local metabolism and better venouslymphatic circulation.

\section{References}

1. Gheza G, Bissolotti L. Ossigeno-ozonoterapia mediante infiltrazione intraarticolare nella patologia del ginocchio. Rivista Italiana di Ossigeno-Ozonoterapia 2003;2:63-6.

2. Gjonovich A, Sattin GF, Girotto L, Bordin M. Lombalgie ribelli: 1'ossigeno-ozono terapia a confronto con altre metodiche. Rivista di Neuroradiologia 2001;14:35-8.

3. Del Favero A. Le strategie preventive per ridurre la tossicità gastrointestinale da FANS. Informazioni sui Farmaci 2007;31:122-5.

4. Marianio F. L'ossigeno ozono nella medicina fisica e riabiltativa. In: Valobra GN, Gatto R, Monticone M, eds. Trattato di medicina fisica e riabilitazione. Torino: UTET; 2000. pp 13551360.

5. Richelmi P, Valdenassi L, Bertè F. New aspect of oxigen-ozone therapy. Eur J Clin Invest 2003;33:23-62.

6. Bonetti M, Cotticelli B, Richelmi P. Rofecoxib e O2-O3 terapia vs $\mathrm{O} 2-\mathrm{O} 3$ terapia nel trattamento della spondiloartrosi. Ozonoterapia 2002;1.

7. Fabris G. Il consenso informato in ossigeno-ozonoterapia. Rivista Italiana di Ossigeno-Ozonoterapia 2003;2.

8. Parfitt JR, Driman DK. Pathological effects of drugs on the gastrointestinal tract: a review. Human Pathol 2007;38:527-36. 